collapsed state; we had to content ourselves with plugging the ragina with iodoform gauze. As might be expected, peritonitis set in, and she died on April 5 th.

M. R., aged 25 years.

CASE $v$.

History.-First child, craniotomy three years ago; when five months pregnant asked to have Porlo done at full term, as had been do to M. A., her friend (Case III). Came to hospital when labour had commenced. Operated on May 14 th, 1900, and a living child removed Discharged cured on June $6 ! h$

M. B., aged 34 .

$$
\text { CASE ri. }
$$

History.-First child born naturally 17 years previous; no subsequent conception until the present. Had been thirty-six hours in labour when brought to hospital. Operated on May 28th, 1900, and a living child removed. Discharged cured on July rst.

M. W., aged 40 years.

$$
\text { CASE VII. }
$$

Histcry.-Four first children born naturally; fifth and sixth born dead at rull term; seventh born dead at seven months; eighth miscarriage at four months; ninth born dead at full term. For her tenth confinement she was brought to hospital aiter forty-eight hours in labour. In addition to extreme pelvic distortion her thighs were labour. In addition to extreme pelvic distortion her thighs were
flexed on the abdomen and ankylosed in this position, and considerable difficulty was experienced in performing tho operation, so close were the knees on the abdomen. However, a living child was extracted, and hoth left hospital in perfect health on July 6tl. The operation was performed on June 13 th, 1900 .

Case vili.

M. B., aged 20 years.

History. $-\Lambda$ typical rachitic dwarf, with a conjugate of under 2 in Operated on December 5 th, 1900 . The incision in the uterine wall went right through the placenta. Mother and child left hospital in January,

\section{CASE IX.}

M. B, aged 7 years.

History. - A typical rachitic dwarf with extreme pelvic distortion. Four days in labour before arrival at hospital; extremely collapsed, but fetal heart audible, though sounds very weak. Operated on February r th, rgor. Discharged cured on March 8 th.

M. I., aged 27 years

$$
\text { CASE } X \text {. }
$$

History. - Two children eleven and nine years previously. For last five sears had constant pain in back and hips (evidently osteomalacia); was brought to hospital at midnight on December 7 th, rgor. Operation performed in indifferent light. The ligature being applied not sufficiently tight, the stump was found live and bleeding next morning. A second ligature was applied, but this must have interfered with the a ōhesions already formed, and opened the door to septic material, and she died of peritonitis on the fifth day. The child only just breathed, so is the only one of the twolve children which was born, one may say, dead. In all subsequent cases the serrenoeud was used, and this life would have been saved had it been used.

M. S., aged 25 ycars.

CASE XI.

History.-One child born naturally; one miscarriage ; osteomalacic pclvis. Operated on May 8 th, I903, and a healthy child born. Discharged cured on Junc 5 th, 1903 .

M. M., aged ${ }_{3} 6$ years.

CASE XII.

History.-First confinement ; extremc contraction of outlet barely admitting two fingers. Operated on August 22 nd. Child, 8 months, had to be wrapped in cotton wool, but got on well. Discharged cured on September. 3 oth.

It will be noticed that in the cases of the nine women who recovered the period spent in hospital averaged only thirty days.

\section{A NOTE ON PORRO'S OPERATION AND A} SUGGESTED MODIFICATION.

By WILliaM H. HORROCKS, F.R.C.S.ENG., Honorary Surgeon, Bradford Royal Infirmary.

Porro's operation is fortunately a rare occurrence, but it is an undertaking which may fall to the lot of any surgeon, so that any method which simplifies the procedure is of interest to the profession. The lines of the operation carried out in this method were suggested by the treatment of uterine fibroids, and in the case which is now recorded gave most satisfactory results.

Porro's operation was first undertaken in 1876 , and is thus described

After the uterus has been emptied, as in an ordinary Caesarean section it is drawn out of the abdominal wound and surrounded by a wire at its lower segment. The uterus with its appendages is then cut away.
In 1878 Müller modified the operation by tilting the unopened uterus out of the wound, and then surrounding the neck of the uterus near the internal os with a loop of wire, or, still better, with an elastic tube. Only after this had been done was the uterus incised. The evacuation of the uterine contents was completed as quickly as possible, and the elastic tube was not taken off until the uterine wound was completely closed by sutures.

With some slight modifications this has been made the method of operation until the present time. In considering the choice of operation between Caesarean section and the modification proposed by Porro there are certain points which are greatly in favour of Porro's operation. Broadly it may be said that one or other of these operations is indicated. when the deformity of the pelvis is so great as to render delivery without craniotomy impossible, where some tumour growing from the cervix uteri or the sacrum blocks the pelvic cavity. In the choice between the two operations the question of leaving the uterus as in Caesarean section has always seemed a doubtful point, although cases are recorded by French surgeons in which several operations have been performed on the same woman. Of late it has been the custom in the Caesarean section to sterilize the patient by dividing the Fallopian tubes. Another drawback to Caesarean section is the suture of the uterine wall. The sutures necessarily passing through tissues undergoing rapid disintegration in close proximity to a part very liable to septic infection.

The time of operation for Porro's modification may be selected at any time when the child is viablewithout allowing the onset of uterine pains to exhaust a patient who has to undergo a formidable operation. 'The length of incision in the raiddle line should be such as to allow the uterus, with its contents, to be drawn outside the abdomen, as in this way it is more satisfactorily handled, and it may be packed round so as to prevent the uterine contents soiling the general peritoneal cavity.

Before drawing out the uterus it may be necessary to ligature in two places the broad ligaments on each side and divide between the ligatures. The uterus is then drawn out and the peritoneum stripped from its two sides until the neck of the uterus is reached with the finger. The uterine artery is felts for on each side, and a Macewen's needle armed with silk is passed through the tissues so as to command the artery. On one side this ligature is tied; on the other side it is left loose, but can be easily tied, if necessary, to control haemorrhage. The anterior wall of the uterus is now examined, and its peritoneal covering divided, avoiding as far as possible visible uterine sinuses. The muscular tissue is torn through with a blunt director until the outer surface of the membianes is exposed. The membranes are now opened and the opening enlarged so as easily to draw out the child. As soon as natural respiration is established the cord is clamped between two Spencer Wells's forceps and divided and the child handed over to the care of the bystander. The uterine cavity is now emptied of fluid, the cord with the forceps is returned into the uterine cavity but no attempt is made to remove the placenta or membranes. A flat sponge is packed into the uterine cavity and the opening drawn together. A second ligature is now tightened round the uterine artery and the uterus drawn well up and divided as low down as possible. Any oozing points in the stump are thus ligatured and the two. flaps of uterine tissue brought together with buried catgut sutures through the uterine walls and silk stitches through its peritoneal covering. Before forming the uterine stump care should be taken to define the extent of the bladder by passing the sound into the bladder. The stump should be so shaped that the flaps are capable of a good broad adhesive surface, one flap fitting the other as tar as possible. Any loose membrane inside the cavity of the neck may be scraped away and the raised mucuous membrane touched with strong: carbolic solution. All clots are now cleared away, and the pelvis carefully dried. The question of drainage is one on. which operators will differ. On the whole it seems gafer to place a Keith's tube in Douglas's pouch, as there may be - some oozing from the uterine tissues, and the possibility of soiling the pelvis by some oozing from the remaining segment of the uterus must be considered. The abdominal walk is thus brought together with deep and through stitches, sup-ported with strips of aseptic strapping and a firm bandage applied over a large dressing of antiseptic wool. The case on which this method of operation was practised is as follows:

A. B., a weaver, aged 43 , was sent into the Bradford Royal Infirmary 
on June $20 t h, 1903$, by Dr. Gray, who was of opinion that she had a pelvic tumour which would prevent the passage of a child by the natural way. She was in fairly good health, and had no symptoms of haemorrhage or pressure from the pelvic tumour. The examination of the abdomen showed the top of the uterus well above the umbilicus. The uterine walls showed prominent nodules at the top and upper part, and parts of the fetus could be felt in utero. The pelvic examination showed a rounded mass in Douglas's pouch which was firmly wedged .and extended to the pelvic wall, displacing the uterus forwards.

Operation.-On June ${ }_{23}$ rd chloroform was administered and the abdominal wall divided by a long median incision extending from above the umbilicus almost to the pubes. On exposing the uterus a large fibroid tumour was found on its anterior wall, which was pedunculated and bled somewhat freely on attempting to bring out the uterus. A thick band of omentum was adherent to the upper part of the uterus. The omentum was first divided between ligatures; the broad ligaments on each side were tied in two places and divided between the ligatures. The loose tissue on each side of the uterus was then separated with the finger, and the uterine arteries felt low down on each side. Macewen's needle threaded with thick silk was passed round the arteries, and on the right side this ligature was tied, but the left ligature was not tightened. The uterus was then drawn out at the abdominal cavity and packed round with flat sponges and towels. An inclsion was made in its anterior wall about 5 in. in depth, and the muscular wall torn through to the same extent. The membrane was then carefully opened and the finger passed in, to find the position of the placenta.

The opening in the membranes was then enlarged, and the child readily withdrawn. Respiration set in at once, and the cord was cut between two pressure forceps.

The liquor amnii was drained over the side to avoid soiling the peritoneum. The cord with the forceps was returned, and a flat sponge placed in the uterine cavity, while the margins in the opening of the uterus were pressed together. The uterus was then drawn forwards, and with some difficulty the fibroid tumour was drawn out of the pelvis. Both uterine arteries were now tied securely, and the uterus cut through low down, so as to make two flaps of uterine tissue. There was very little haemorrhage from this stump, which was brought together with buried catgut sutures and silk sutures through the peritoneum. 'The pelvis was then cleared of clots, etc., and a Keith's drainage tube inserted in the pelvis, with its upper end projecting from the lower part of the wound. The abdominal wall was brought together with silkworm-gut sutures, the separate layers being united with buried catgut sutures. The operation lasted one hour, and at its termination the pulse was 80 and good in character.

After-history. - The patient made a good recovery, the only incident to be noted was a small collection of pus in the pelvis which necessitated the reintroduction of a drainage tube for some days.

The special point in the operation was the small amount of shock which the patient suffered, in fact, the pulse was better than after the termination of an ordinary labour. This was due chiefly to the small amount of haemorrhage which was easily controlled by the ligatures. The question of tightening the second ligatures on the uterine artery before extracting the child is one for future consideration.

\section{A CASE OF VESICULAR MOLE OF UNUSUAL SIZE.}

BY THOMAS SLATER JONES, L.R.C.P.LOND.,M.R.C.S.ENG

Mrs. C., aged 48 years, had had eight children. Five years ago she passed a similar mole, but much smaller. Two years ago she had a child at full term. This child is distinctly syphilitic. She had an attack of rheumatic fever abou eighteen months ago. Menstruation had ceased for seven months. The patient told me that for a month she had a more or less bloody dischiarge, with uterine pains off and on.

On August 15th, 1903, when I saw her, she had strong labour pains, a copious, weak sanguinous discharge in which could be seen an occasional cyst of the hydatidiform mole. On external palpation the uterus was felt to be very much distended; it extended up to the ensiform cartilage. No fetus could be felt (as she was thin this would have been an easy matter to make out). The os was fairly dilated, and masses of the cysts, which felt soft and peculiar to the finger-not like the feel of placenta praevia at all-but with a sensation to the finger quite characteristic of the condition, presented.

After the patient had been put under chioroform, I introduced my hand into the uterus, and got the whole of the masses of cysts away without much difficulty. This was fortunate, as frequently in these cases there are considerable adhesions to the interior of the uterus, whose wall may be very much thinned in places. Haemorrhage, too, is often excessive, but by keeping one's hand well over the uterus and by injecting ergotine hypodermically, this anxious complication did not occur. Subsequently the patient made an uneventful recovery.
The mass of cysts weighed $5 \mathrm{lb} .4 \mathrm{oz}$. The cysts presented somewhat the appearance of grapes; the largest measured about $1 \frac{1}{2}$ in. longitudinally, the smallest being smaller than a pin's head. 'They contained a gelatinous material slightly

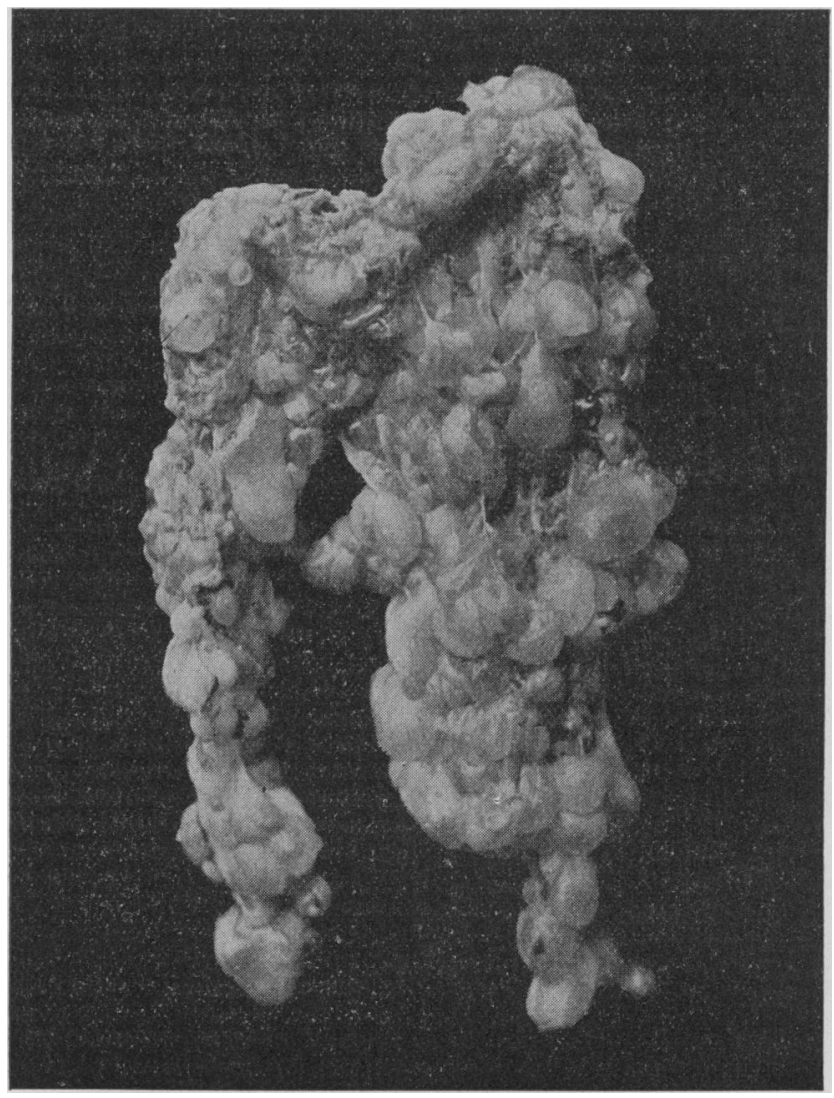

Fig. r. - Photograph of a very small portion of the mole.

tinged with red enclosed in a translucent, glistening, ovoid envelope. Each cyst was attached by an independent peduncle, which did not arise from a common stalk as in grapes, but apparently one from another.

Report from Clinical Research Association.

This section exhibits chorionic villi in various stages of mucoid degeneration. Masses of epithelium have resulted from proliferation of the syncrtium covering the villi, and some of these are also degenerating. There is no definite growth like "deciduoma malignum."

\section{SOME DECEPTIVE ABDOMINAL CONDITIONS AND THE QUESTION OF OPERATION.*}

\section{By A. H. TUBBY, M.S., F.R.C.S.,}

Surgeon, Westminster and Evelina Hospitals.

When I was honoured by being asked to read a paper before this Branch of the Association, it appeared to me that I could not enlist your interest better than by choosing this subject. because it is common ground to all of us, and the questions of operation and of no operation are constantly arising. The maze of symptoms in these abdominal cases is sometimes so tangled that we welcome any clue, however slight, to guide us in our difficulties. It must be admitted that the method of settling the diagnosis by making an exploratory operation in all doubtful cases is one which is certainly not feasible in private practice, and it cannot be justly said to be in the best interests of any patient if constantly employed. It is indeed strongly to be deprecated, because it savours merely of the art of surgery, and not of the science. He is a poor surgeon who finds himself compelled to cut the Gordian knot of his difficulties by acting on the formula: "Let us open the abdomen and look inside." The risks of a simple section are, it is true, small, but they are appreciable, and no patient * Read at a meeting of the East Surrey District of the South-Eastern Branch of the British Medical Association. 